\title{
Physics and applications of slow and fast light in semiconductor optical waveguides
}

Mørk, Jesper; Chen, Yaohui; Ek, Sara; Pu, Minhao; Yvind, Kresten

Publication date:

2012

Document Version

Publisher's PDF, also known as Version of record

Link back to DTU Orbit

Citation (APA):

Mørk, J., Chen, Y., Ek, S., Pu, M., \& Yvind, K. (2012). Physics and applications of slow and fast light in semiconductor optical waveguides. Abstract from Conference on Integrated Photonics Research, Silicon and Nanophotonics, Colorado Springs, Colorado, United States.

\section{General rights}

Copyright and moral rights for the publications made accessible in the public portal are retained by the authors and/or other copyright owners and it is a condition of accessing publications that users recognise and abide by the legal requirements associated with these rights.

- Users may download and print one copy of any publication from the public portal for the purpose of private study or research.

- You may not further distribute the material or use it for any profit-making activity or commercial gain

- You may freely distribute the URL identifying the publication in the public portal

If you believe that this document breaches copyright please contact us providing details, and we will remove access to the work immediately and investigate your claim. 


\title{
Physics and applications of slow and fast light in semiconductor optical waveguides
}

\author{
Jesper Mørk, Yaohui Chen, Sara Ek, Minhao Pu, and Kresten Yvind \\ Department of Photonics Engineering, Technical University of Denmark, DK-2800 Kongens Lyngby, Denmark. \\ jesm@fotonik.dtu.dk
}

\begin{abstract}
We review the physics of slow and fast light based on coherent population oscillations in active semiconductor waveguides. Exploiting these effects, microwave phase shifters realizing 360 degree phase shift and operating at tens of $\mathrm{GHz}$ have been realized.

OCIS codes: (230.0250) Optoelectronics; (230.5980) Semiconductor optical amplifiers; (230.1150) All-optical devices.
\end{abstract}

\section{Summary}

Coherent wave mixing effects in nonlinear media provide the possibility of changing the amplitude and phase of the frequency components of an optical signal. In particular, the process of coherent population oscillations (CPO for short) was demonstrated to enable the control of the group velocity of light, thus realizing slow-light propagation [1]. It is well-known that four-wave mixing effects mediated by carrier density pulsations in active semiconductor waveguides can be very strong and it is therefore natural to seek to exploit these effects to control the speed of light in a very compact and electrically controllable device. For many applications within microwave photonics it is rather the control of the phase shift of the microwave-modulated envelope of the optical signal that is of interest and recent progress within the field has allowed the realization of a 360 degrees phase shift at microwave frequencies of several tens of $\mathrm{GHz}[2]$

In this paper we review the physics of slow and fast light effects in semiconductor active waveguides [3] as well as recent progress towards the application of these effects within microwave photonics [4]. In particular, we introduce and explain the use of optical filtering [5] to increase the magnitude of the phase shift and the microwave frequency at which it can be realized. For practical applications, the signal to noise ratio is important and we discuss the tradeoffs at play here [6].

Finally we discuss the possibility of enhancing CPO mediated phase shifts by exploiting the additional effect of structural slow light in active photonic crystal waveguides.

\section{Acknowledgements}

Part of the work was performed within the framework of the European FP-7 Project "GOSPEL" and the authors acknowledge the collaborations within this project. [4]

\section{References}

[1] M. S. Bigelow, N. N. Lepeshkin and R. W. Boyd, Phys. Rev. Lett., Vol. 90, 113903 (2003).

[2] W. Xue, S. Sales, J. Capmany, and J. Mørk, Opt. Express , Vol. 18, 6156 (2010).

[3] J. Mørk, F. Öhman, M. van der Poel, Y. Chen, P. Lunnemann, and K. Yvind, Laser \& Photon. Rev., Vol. 3, 30 (2009).

[4] M. Santagiustina et al., IEEE Photon. Soc. Newsletter, 5-12 (Feb. 2012).

[5] Y. Chen, W. Xue, F. Öhman, and J. Mørk, J. Lightwave Technology, Vol. 26, 3734 (2008).

[6] S. Ó Dúill, E. Shumakher, and G. Eisenstein, J. Lightwave Technol., Vol. 28, 791 (2010). 